\title{
VIBRATION REDUCTION OF A SINGLE CYLINDER \\ RECIPROCATING COMPRESSOR BASED ON MULTI-STAGE \\ BALANCING
}

\section{AUTHORS:}

N. LEVECQUE*, J. MAHFOUD*, D. VIOLETTE**, G. FERRARIS* and R. DUFOUR*

*Université de Lyon, CNRS, INSA-Lyon, LaMCoS UMR5259, F69621, Villeurbanne, France

** Danfoss Commercial Compressors, F01600, France.

\section{COMPLETE ADDRESS OF CORRESPONDING AUTHOR:}

Dr Jarir Mahfoud

Université de Lyon, CNRS, INSA Lyon, LaMCoS - UMR 5259, 8, rue des Sciences, 69621 Villurbanne Cedex, France

Phone: 33 - 4.72.43.89.39, Fax: 33 - 4.72.43.89.30,

Jarir.mahfoud@insa-lyon.fr

The manuscript contains 29 double-spaced pages, 3 tables and 8 figures 


\section{ABSTRACT}

Basically, a reciprocating compressor consists of three main mechanical subsets: the hermetic housing, the crankcase and the rotor-crankshaft assembly. The counterweight mass located on the rotor-crankshaft is designed to balance the eccentric masses of the slider-crank mechanism which predominate in comparison to the residual distributed unbalance masses due to manufacturing. However, excessive vibration levels can be observed. The objective of the study is to perform a reliable finite element model for balancing the compressor by taking into account the dynamic behavior of the three subsets. The rotor-crankshaft assembly is considered as a flexible body, while the crankcase and the housing are assumed to be rigid. The rotor-crankshaft model is updated by using experimental modal analysis at rest. The characteristics of the fluid film bearings are speed of rotation dependant. The forces of the pressure and of the slider-crank mechanism are expanded by using Fourier transformation. The Influence Coefficient Method is used to investigate several balancing solutions to reduce the vibratory levels of the target plane located on the three main subsets. The experiments carried out show that this multi-stage balancing procedure is rather more efficient than a classical approach based only on the dynamic balancing of the rotor crankshaft assembly.

\section{KEYWORDS:}

Balancing, Dynamic behavior, Compressor, Finite element, Experiments. 


\section{1- INTRODUCTION}

Single cylinder reciprocating compressors are widely used in several types of refrigerant applications. They are driven by an asynchronous electrical motor and their operating speed depends on the power supply frequency (50 or $60 \mathrm{~Hz}$ ). Generally speaking, they consist of three main subsets: (1) a slider crank mechanism composed of a piston, a connecting rod, a crankshaft equipped with a counterweight mass and an electrical rotor, (2) a crankcase equipped with an electrical stator and (3) hermetic housing. These subsets are linked altogether by different types of suspension: the crankshaft is linked to the crankcase by two fluid film bearings and an air gap, the crankcase is linked to the housing by springs and, lastly, the housing is linked to the frame by grommets and by suction and discharge pipes. In brief, a single cylinder compressor is a multi-stage system subject to vibration even after balancing has been carried out.

In order to reduce the effect of the eccentric masses (crankpin and crank arm masses, rotating mass of the connecting rod), static balancing consists in positioning a counterweight in a plane close to the connecting rod plane. To avoid excitation of the moment due to the offset of these two planes, another balancing plane, positioned classically on the electrical rotor, is used for dynamic balancing. Therefore dynamic balancing has to be carried out on the crankshaft equipped with the electrical rotor and a ring whose mass is equivalent to the rotating masses. Unfortunately, such a balancing does not take into account the dynamic behavior of the three main subsets. Consequently, the responses of the latter can be overpronounced. Noise and mechanical problems can occur, such as rotor-to-stator or bearing rubbing and failures at pipe weld spots. 
Complementing the balancing techniques, several technological solutions have been proposed to obtain optimal vibration reduction. Mention can be made of attempts to optimize the locations of the counterweight and the internal suspensions [1], and to introduce a piston axis offset [2]. Moreover, the multistage balancing method presented in $[3,4]$ was applied to rotary compressors composed of two subsets.

The objective of the study is to develop a simple balancing procedure for the operators that could be applied on a single cylinder reciprocating compressors. It aims at the reduction of the vibration levels of the three subsets constituting the compressor. This type of compressor has the advantage to be efficient and cheap, so the additional cost due to balancing must be negligible. The method developed is a model based balancing method taking into account the geometrical definition of the different compressor elements. The magnetic attraction forces and the interaction between the three subsets constituting the compressor are considered.

The initial unbalances are mainly due to the eccentric masses of the crankshaft (crank-pin, crank-arms, counterweight, etc.) and of the rotating part of the connecting rod. The alternative part of the connecting rod, added with piston ring and pin masses are in a translation movement and cannot be fully balanced by a rotating mass. The geometrical dispersion, of the rotating part, measured was found to be less than $5 \%$. The main contribution of this dispersion concerns the eccentric mass and too particularly the counterweight mass.

Consequently, the residual unbalance distributed masses due to manufacturing are neglected.

Section 2 focuses on the data of a refrigeration compressor to illustrate the balancing approach. The Finite Element (FE) models of the three subsets are 
combined with rotordynamics theory, see Section 2. Moreover, the constant and synchronous terms of the forcing excitations are taken into account. The Fourier expansion of the slider-crank forces provides constant, synchronous and non synchronous forces. The constant force permits evaluating the bearing characteristics which are speed of rotation dependent. The synchronous force is used for the balancing and combined with the sup-synchronous forces for predicting the mass unbalance response (Section 3). The influence coefficient technique provides multi-stage balancing based on two speeds of rotation, two correction planes and several target planes located on the three subsets and especially at the anchorage points on the housing of the suction and discharge pipes. The corrective mass calculated by the proposed multi-stage balancing based on a model and by classical dynamic balancing based on experimental tests carried out only on the equivalent rotating part, are implemented in two identical compressor prototypes. The proposed balancing efficiency is investigated by analyzing the measured steady state mass unbalance responses of the two prototypes under several operating conditions. Then the advantages and the limitations of the proposed multi-stage balancing are discussed.

\section{2- SINGLE-CYLINDER REFRIGERANT COMPRESSOR}

The compressor sketched in Fig.1 is composed of three subsets: the rotorcrankshaft assembly, which is a rotating part; and the stator-crankcase assembly and the hermetic housing, which are non rotating parts. The rotor-crankshaft assembly is connected to the stator - crankcase assembly by the fluid film bearings and the magnetic attraction between the electrical rotor and the stator. The crankcase is connected to the hermetic housing by an internal suspension composed of springs and the discharge pipe, and the housing is mounted on an external suspension 
composed of grommets and the suction and discharge pipes. The stiffness of the pipes is assumed to be neglected regarding the stiffness of the springs and grommets.

An industrial hermetic reciprocating single-cylinder refrigeration compressor is investigated to illustrate the different steps of the proposed balancing approach. The compressor chosen is able to run either at $50 \mathrm{~Hz}$ or at $60 \mathrm{~Hz}$ and has a swept volume of $68 \mathrm{~cm}^{3}$ by revolution. It provides a cooling capacity of $5.7 \mathrm{~kW}$ for a power input of $2.9 \mathrm{~kW}$ at $50 \mathrm{~Hz}$ with an evaporating temperature of $-10^{\circ} \mathrm{C}$ and a condensing temperature of $45^{\circ} \mathrm{C}$. The net mass of the compressor is $26 \mathrm{~kg}$ while the rotorcrankshaft assembly, stator-crankcase assembly and housing have roughly the following masses: $3.5 \mathrm{~kg}, 15 \mathrm{~kg}$, and $7 \mathrm{~kg}$, respectively.

\section{3- FINITE-ELEMENT MODEL}

\section{1- Whole Compressor}

The FE model, shown in Fig. 2, is governed by the rotordynamics theory presented in [5]. Each node contains the four degrees of freedom (DOF) of the bending motion: two lateral translations and the two associated rotations. The rotating part, considered as flexural, is modeled with two node beam elements. The rotor-crankshaft assembly and the hermetic housing are considered rigid and are modeled with rigid beam elements. Their mass properties are modeled with additional mass elements located at their centre of inertia. The bearings, that relate the rotor to the crankcase assembly (nodes \#30, 37 \& 65 on Figure 2), are modeled with two-node bearing elements whose stiffness and damping parameters are speed of rotation dependent (modeling detailed in section 3.4). Side-pull forces between the electric rotor and the stator are taken into account by using distributed additional two 
node elements (relating elements $51-56$ of the stator and 3-8 of the electrical rotor) with negative stiffness, [6]. The internal suspensions (relating the crankcase assembly to the housing) and the grommets (relating the whole compressor to the foundations) are modeled by using two-node elements, located on the rotor axis and containing transverse and angular parameters. The modeling of the rotating parts is detailed in the next section. After assembly, the unbalance response of the compressor is governed by the matrix equations:

$$
\left[\mathbf{M}_{R}+\mathbf{M}_{N R}\right] \ddot{\mathbf{X}}+\left[\mathbf{C}_{G}(\Omega)+\mathbf{C}_{B}(\Omega)+\mathbf{C}_{S}\right] \dot{\mathbf{X}}+\left[\mathbf{K}_{R}+\mathbf{K}_{B}(\Omega)+\mathbf{K}_{S P}+\mathbf{K}_{S}\right] \mathbf{X}=\mathbf{F}(\Omega),
$$

with $\Omega$, being the constant speed of rotation, $\mathbf{X}$ the displacement vector containing all the bending DOF of the assembly, $\mathbf{M}_{R}$ and $\mathbf{K}_{R}$ the classical mass and stiffness matrices of the rotating part; $\mathbf{C}_{G}(\Omega)$, the non-symmetric gyroscopic matrix; $\mathbf{C}_{B}(\Omega)$ and $\mathbf{K}_{B}(\Omega)$, the damping and stiffness matrices due to the bearings; $\mathbf{M}_{N R}$, the mass matrix of the non-rotating parts; $\mathbf{K}_{s}$ and $\mathbf{C}_{s}$, the stiffness and damping matrices associated with the suspensions; $\mathbf{K}_{S P}$, the anti-stiffness matrix associated with the side-pull forces. The external force vector $F(\Omega, n \Omega)$,

$$
\mathbf{F}(\Omega, n \Omega)=\mathbf{F}_{C}(\Omega)+\mathbf{F}_{C M}(\Omega)+\mathbf{F}_{P+C R}(\Omega, n \Omega),
$$

contains $F_{C}(\Omega)$, the force vector due to the eccentric masses of the crankshaft, $\mathbf{F}_{C M}(\Omega)$, the force vector of the correction masses, and $\mathbf{F}_{P+C R}(\Omega, n \Omega)$ the slider-crank force vector related to the piston, connecting rod and cylinder pressure. In what follows particular attention is paid to the rotating part, slider-crank forces and bearings. 


\section{2- Rotating part}

Figure 3 represents the general modelling of the rotating parts with the used elements (numbered from 1 to 41 ) and the corresponding nodes that are denoted by italic underlined numbers. The rotor-crankshaft assembly is mainly modelled with 41 shaft elements. Rigid disk elements $\left(D_{1} \& D_{2}\right)$ with a mean radius are used for modelling the counterweight. Crankshaft dissymmetry is taken into account by applying mass unbalances in response calculation. The crankpin assumes the angular reference. Therefore the unbalance masses, with a $0^{\circ}$ phase are located on nodes $(16,19,21,23)$ to model the crankpin and crank-arm dissymmetry while unbalance masses, with a $180^{\circ}$ phase, are applied on nodes $(13,15)$ to consider the counterweight. Consequently the total unbalance masses situated at $0^{\circ}$ is 3983 g.mm, and at $180^{\circ}, 4458$ g.mm.

The FE model was updated by carrying out an experimental modal analysis on a free-free rotor crankshaft assembly. The Roving hammer technique was used to obtain the bending mode shapes with the data acquisition system LMS-CadaX. To update the natural frequencies, the diameters of shaft elements corresponding to the crank-pin and crank-arm (32 to 35 ) were reduced to make the elements more flexible. It should be mentioned that this modification had no influence on the mass properties since the shaft elements were modelled without mass and the mass effect was considered with rigid disk elements (D3 for the mass effect of the crankpin, D4-D6 for the mass effect of the different sections of the crank-arm).

The electrical rotor, made of steel laminations joined together with aluminium bars, is fitted onto the crankshaft, made of cast iron. The material properties are presented in Table 1. 


\section{3- Slider-crank forces}

The pressure force $P_{r}$ is applied on the piston and on the crankcase and transmitted to the crankshaft by the connecting rod. The transmitted forces are denoted Qx and Qz (Fig. 4) and they vary with respect to the angular position $\vartheta$. Only the synchronous component of these forces is considered for the balancing procedures. The constant component corresponds to the load supported by the bearings. Let $P, B, M$, and $O$ be the centres of the piston, of the connecting rod, of the crank-pin and of the crankshaft, respectively. Let $m_{C R}, I, I_{C R}, \phi$ be the mass, length, inertia, and auxiliary angle of the connecting rod. Consequently its alternative and rotating masses are $m_{r e}=\frac{b}{l} m_{C R}$ and $m_{r o}=\frac{a}{l} m_{C R}$. Let $r$ be the eccentricity of the crank-pin, $x_{p}$, and $m_{p}$, the position and the mass of the piston. The angular position of the crankpin is $\vartheta$. The variable $x_{p}$ is linked to $\vartheta$ the main variable of the mechanism [7, 8] and depends on the cylinder volume. The transmitted force components $Q_{x}$ and $Q_{z}$ have the following expressions:

$$
\begin{gathered}
Q_{x}=\left(m_{r e}+m_{p}\right)\left(-\ddot{x}_{p}\right)+m_{r o} r \dot{\vartheta}^{2} \cos \vartheta-P_{r}, \\
Q_{z}=\frac{1}{I \cos \phi}\left(I_{C R}-m_{C R} a b\right) \ddot{\phi}+\left[\left(m_{p}+m_{r e}\right)\left(-\ddot{x}_{p}\right)-P_{r}\right] \tan \phi-m_{r o} r \dot{\vartheta}^{2} \sin \vartheta
\end{gathered}
$$

The pressure diagram taken into account corresponds to the operating condition corresponding to evaporating and condensation temperatures: $-10 \% 45^{\circ} \mathrm{C}$. In order to extract the synchronous component of the efforts for the balancing considerations, each force component is fitted first by fifteenth order polynomials (Fig. 5) and then expanded in a Fourier series: 


$$
Q(\vartheta)=a_{0}+\sum_{k=1}^{N} a_{k} \cos (k \vartheta)+b_{k} \sin (k \vartheta)
$$

where the coefficients $a_{k}$ and $b_{k}$ are calculated by the coefficients of the polynomials. The constant terms $a_{x 0}$ and $a_{z 0}$, corresponding to static forces, are calculated for both the $x$ and z-components: $a_{x 0}=2969 \mathrm{~N}, a_{z 0}=218 \mathrm{~N}$. The crankpin is loaded by the static force $F_{p}$, given by:

$$
F_{p}=\frac{1}{2} \sqrt{a_{x 0}^{2}+a_{z 0}^{2}}=1489 \mathrm{~N}
$$

For the higher order, the $\mathrm{x}$-component coefficients are the largest and are the only ones used in the compressor dynamics (Table 2). The z-component contributes only on the constant term corresponding to the load supported by the bearings. The compressor balancing procedure is based only on the first order coefficients.

\section{4- Bearing characteristics}

Stiffness and damping coefficients are evaluated by using the tables proposed by Someya [9]. First of all, the Sommerfeld number S should be estimated. Let $\mu$ be the oil film viscosity, $\Omega=\dot{\theta}$ the speed of rotation, $L, D, C_{p}, F$ the length, the diameter, the gap, and the static load of the bearing, respectively.

$$
S=\frac{\mu \Omega L D}{F}\left(\frac{D}{2 C_{p}}\right)^{2}
$$

The upper bearing is made of two bearing models (L/D 1, node \#37 on Figure 2, and L/D 0.5, node 30) while the lower bearing has a ratio L/D 1 (node \#65). The reactions $F$ on each bearing are deduced from relation (6). The stiffness and damping coefficients of the three bearings are calculated for 3000 and $3600 \mathrm{r} / \mathrm{min}$. 


\section{4- PROPOSED MULTI-STAGE BALANCING}

\section{1- Influence Coefficient Method}

The influence coefficients (IC) method is a well known experimental balancing method [10]. It consists of evaluating the influence of trial masses on the displacements at given planes, called measuring planes. The method assumes that the displacements are linearly proportional to the trial weights and that the initial unknown unbalance can be represented by a discrete finite number of unbalance moments that are placed on chosen balancing planes [11, 12]:

$$
\mathbf{V}_{i n i}=\mathbf{C} \mathbf{B}_{i n i} \text {. }
$$

$\mathbf{V}_{i n i}$ is the vector of radial displacements due to the initial unknown unbalance $\mathbf{B}_{i n i}$. The elements of $\mathbf{V}$ and $\mathbf{B}$ contain magnitude and phase information with respect to the reference phase, defined previously. C is the influence coefficient matrix. The method aims at determining the balancing weights $\mathbf{B}_{c}$ to be placed at the chosen balancing planes so that the magnitudes of radial displacements, measured at the measuring planes, are minimized for different speeds of rotation:

$$
\mathbf{C}\left(\mathbf{B}_{i n i}+\mathbf{B}_{c}\right)=0
$$

Here, the IC method follows a numerical approach. The IC matrix represents the system and is determined by using trial weights BT and by predicting the resulting displacements VR at given planes, known as target planes here:

$$
\begin{aligned}
& \mathbf{C}\left(\mathbf{B}_{i n i}+\mathbf{B}_{T}\right)=\mathbf{V}_{R}, \\
& \mathbf{C}=\mathbf{B}_{T}^{-1}\left(\mathbf{V}_{R}-\mathbf{V}_{i n i}\right) .
\end{aligned}
$$


The correction weights are calculated either by direct inversion if the numbers of balancing planes and of target planes are equal:

$$
\mathbf{B}_{C}=-\mathbf{C}^{-1} \mathbf{V}_{\text {ini }} \text {, }
$$

or by least squares technique, if not $[13,14]$ :

$$
\mathbf{B}_{C}=-\left[\overline{\mathbf{C}}^{t} \mathbf{C}\right]^{-1} \overline{\mathbf{C}}^{t} \mathbf{V}_{i n i}
$$

where $\overline{\mathbf{C}}$ represents the complex conjugate of matrix $\mathbf{C}$.

\section{2- Balancing procedure}

The IC method with a numerical approach is applied on the compressor model to determine the weights that reduce the vibrations on several target planes situated on different subsets of the compressor. The crankshaft dissymmetry and the slidercrank mechanism generate unbalance forces called initial unbalances. Only the synchronous forces can be balanced, corresponding with the first order of the Fourier series (Fig. 5). The planes at the top of the electrical rotor (BP1) and at the counterweight (BP2) are available technologically in order to place corrective weights. The aim is to reduce vibration levels especially in the target planes (TP1 TP7), where there are specific connections (pipe-housing, grommets-housing, springs-crankcase) and the air gap, (Fig. 2). The calculation of the corrective weights is done successively for single-plane balancing and for two-plane balancing, for one speed (3000 or $3600 \mathrm{r} / \mathrm{min}$ ) and for two speeds (3000 and $3600 \mathrm{r} / \mathrm{min})$. The model successively predicts the responses to the initial unbalances and to the trial weights added to the initial unbalances. The initial unbalances and the calculated corrective weights permit providing predicted responses at the target planes which are compared to responses with the initial unbalances only, see Fig. 6. 
The multi-plane balancing is more efficient than the single-plane balancing. The two-speed balancing, which is more convenient for 50 and $60 \mathrm{~Hz}$ operating conditions, is not really less efficient than the one-speed balancing. The responses calculated at $3000 \mathrm{r} / \mathrm{min}$ and at $3600 \mathrm{r} / \mathrm{min}$ are similar. Consequently only the results at $3000 \mathrm{r} / \mathrm{min}$ for the two-plane and two-speed balancing are presented (Table 3, Fig. $6)$.

Considering the responses predicted by the model, the proposed balancing is efficient, especially for the planes located on the housing. TP 2, TP 3 and TP 7 response planes are similar to the responses of TP 1 and TP 4 but they are not presented here.

\section{5- EXPERIMENTAL VALIDATION}

The objective of the experimental investigation is to implement the proposed multi-stage balancing in a compressor prototype \#1 to evaluate its efficiency regarding the classical dynamic balancing implemented in another similar compressor prototype \#2.

The classical dynamic balancing is carried out on the rotor-crankshaft assembly by using a balancing machine, the two balancing planes described in Section 3.2, and one speed (600 r/min). The balancing quality obtained corresponds to the G6.3 class at $3000 \mathrm{r} / \mathrm{min}$ of the ISO standard.

The prototypes are mounted on a rigid frame by their grommets and by pipes having a specific design with very low stiffness. The mass unbalance responses are measured for different operating conditions by using three tri-axial accelerometers stuck onto the hermetic housings at measurement points MP1 and MP3 
(corresponding to target point TP4 and MP2 (corresponding to target point TP1), see Fig. 7. The piston axis is collinear to the Galilean x-axis, sketched in Fig.7.

The operating conditions took into account the two nominal speeds of rotation corresponding to the 50 and $60 \mathrm{~Hz}$ frequencies, a constant condensation temperature $\left(+45^{\circ} \mathrm{C}\right)$ and an evaporation temperature varying from $-20^{\circ} \mathrm{C}$ to $+10^{\circ} \mathrm{C}$ : $20 / 45^{\circ},-15 / 45^{\circ},-10 / 45^{\circ},-5 / 45^{\circ}, 0 / 45^{\circ}, 5 / 45^{\circ}$ and $10 / 45^{\circ}$. Fig. 8 collects the $X-Y$ vibration magnitudes measured on Prototypes \#1 and \#2. Amplitude values were normalized with respect to the maximum value obtained.

The vibration levels of MP3 and MP2 along $\mathrm{X}$ and of MP1 along $\mathrm{Y}$ are low. The vibration levels of MP3 along $\mathrm{Y}$ and of MP2 and MP1 along $\mathrm{X}$ are high. Therefore it can be established that the steady state housing response is mainly governed by the torsion mode shape around the vertical axis Z. Prototype \#2 provides high vibration levels at the bottom of the housing (MP2). To sum up it can be stated that the housing motion of Prototype \#2 is composed of torsion and strong conical mode shapes while the housing motion of Prototype \#1 is composed of torsion and low cylindrical mode shapes. Prototype \#2 produces a high vibration level in the plane located at the bottom where the grommets and discharge pipe are connected. Moreover the operating conditions have almost no influence on the motion of the housing of Prototype\#1. Broadly speaking, Prototype \#1 provides more satisfactory dynamic behaviour than Prototype \#2.

\section{5- CONCLUSION}

A numerical approach for balancing a single cylinder reciprocating compressor has been presented. Vibration levels of its three subsets were considered and the

constant and synchronous terms of the excitations were taken into account. The 
proposed numerical balancing can be used for rotating machinery whose unbalance masses are fairly well known. This is true for reciprocating compressors. Vibration levels stemming from the proposed balancing were compared with those obtained with a balancing machine and it was shown that this multi-stage balancing is rather more efficient than a classical dynamic balancing focusing only on rotating parts. It can be an alternative solution that saves time and reduces costs. Consequently, it is important to study its sensitivity to production tolerances.

\section{6- REFERENCES}

[1]. K. Kjeldsen, P. Madsen, 1978, Proceeding of Purdue Compressor Technology Conference, edited by James F. Hamilton 55-59. Reduction of compressor vibration by optimizing the locations of the counterweight and the internal springs

[2]. A. Kubota, T. Nagao, K. Tsuboi, T. Kakiuchi, 2006, International publication number WO 2006/049108 A1. Reciprocating compressor

[3]. F. Sève, M.A. Andrianoely, A. Berlioz, R. Dufour, M. Charreyron, 2003, Journal of Sound and Vibration, 264(2), 287-302. Balancing of machinery with flexible variable-speed rotor

[4]. G. Ferraris, M.-A. Andrianoely, A. Berlioz and R. Dufour, 2006, Journal of Sound and Vibration, 292, 3-5, 899-910. Influence of cylinder pressure on the balancing of a rotary compressor

[5]. M. Lalanne, G. Ferraris, 1997, Rotordynamics prediction in engineering, $2^{\text {nd }}$ edition, John Wiley \& Sons 
[6]. L. Marriot, 1994, Proceedings of the International Compressor Engineering Conferences of Purdue, West Lafayette pp. 729-734.. Finite element calculation of rotor side-pull forces in single-phase induction motors

[7]. N. Ishii, K. Imaichi, N. Kagoroku and K. Imasu, 1975, ASME Paper 75$D E T-44$. Vibration of a small reciprocating compressor

[8]. R. Dufour, J. Der Hagopian, M. Lalanne, 1995, Journal of Sound and Vibration, 181(1), 23-41, Transient and steady state dynamic behavior of single cylinder compressors: prediction and experiments

[9]. T. Someya, 1991, Journal-Bearing Databook, Springer-Verlag

[10]. W. C. Foiles, P. E. Allaire, E. J. Gunter, 1998, Shock and Vibration, 5, 325-336. Review: Rotor Balancing

[11]. R.E.D. Bishop, G.M.L. Gladwell, 1959, Journal of Mechanical Engineering for Science 1, 66-77. The vibration and balancing of an unbalance flexible rotor

[12]. J.W. Lund, J. Tonnesen, 1972, ASME Journal of Engineering for Industry 94 233-242. Analyses and experiments on multiplane balancing of a flexible rotor

[13]. T.P. Goodman, 1964, ASME Journal of Engineering for Industry 8 273279. A least squares method for computing balance correction masses

[14]. J. Mahfoudh, J. Der Hagopian, J. Cadoux, 1988, Mécanique, Matériaux, Electricité, Vol. 427, 38-42. Equilibrage multiplans-multivitesses avec des contraintes imposées sur les déplacements 


\section{TABLE CAPTIONS}

Table 1. Material properties of the crankshaft and electrical rotor.

Table 2. Coefficients of the Fourier series.

Table 3. Corrective weights for two-plane and two-speed balancing. 
TABLES

\begin{tabular}{cccccc}
\hline \multicolumn{2}{c}{ Parts of the model } & Composition & $\begin{array}{c}\text { Young's } \\
\text { modulus } \\
(\mathrm{GPa})\end{array}$ & $\begin{array}{c}\text { Mass } \\
\text { density } \\
\left(\mathrm{kg} / \mathrm{m}^{3}\right)\end{array}$ & $\begin{array}{c}\text { Poisson's } \\
\text { ratio }\end{array}$ \\
\hline Crankshaft & Elements 21 to 41 & Cast iron & 180 & 7200 & 0.3 \\
\hline $\begin{array}{c}\text { Electrical } \\
\text { rotor }\end{array}$ & Elements 3 to 8 & $\begin{array}{c}\text { Steel laminations } \\
\text { without aluminium } \\
\text { Elements } 9 \text { to } 14\end{array}$ & 5 & 7800 & 0.3 \\
\hline & $\begin{array}{c}\text { Steel laminations } \\
(50 \%) \text { and aluminium } \\
\text { bars (50\%) }\end{array}$ & 37.5 & 5250 & 0.3 \\
\hline
\end{tabular}

Table 1. Material properties of the crankshaft and electrical rotor 


\begin{tabular}{cccccc} 
& $\mathrm{i}=1$ & $\mathrm{i}=2$ & $\mathrm{i}=3$ & $\mathrm{i}=4$ & $\mathrm{i}=5$ \\
\hline$a_{x i}(\mathrm{~N})$ & -1087 & -2172 & -123 & -23 & -14 \\
\hline$b_{x i}(\mathrm{~N})$ & 748 & 374 & 463 & 210 & 35
\end{tabular}

Table 2. Coefficients of the Fourier series 


\begin{tabular}{ccccc}
\hline Position & Modulus (g.mm) & Radius (mm) & Mass (g) & Phase (9) \\
\hline Plane 1 (node 6) & 824.6 & 26 & 31.7 & -3 \\
Plane 2 (node 48) & 456.8 & 26 & 17.6 & -177 \\
\hline
\end{tabular}

Table 3. Corrective weights for two-plane and two-speed balancing. 


\section{FIGURE CAPTION}

Figure 1 Compressor components.

Figure 2 Finite-element model for the whole compressor

Figure 3 FE model of the rotating part (rotor-crankshaft assembly).

Figure 3 FE model of the rotating part (rotor-crankshaft assembly).

Figure 4 Slider-crank mechanism geometry and transmitted efforts.

Figure 5 Evolution of the forces with the rotation angle.

Figure 6 Predicted responses at target planes \#1, 4, 5 and 6 at $3000 \mathrm{r} / \mathrm{min}$ before (...... ) and after ( $(-)$ ) the proposed balancing.

Figure 7 Experimental set-up showing measurement points MP1, MP2 and MP3.

Figure 8 Dimensionless vibration levels versus operating conditions $-X$ and $Y$ directions at measurement points MP1, MP2 and MP3. Prototype\#1 with proposed balancing ( $(-)$, Prototype\#2 with classical balancing $(\cdots+.$.$) .$ 


\section{FIGURES}

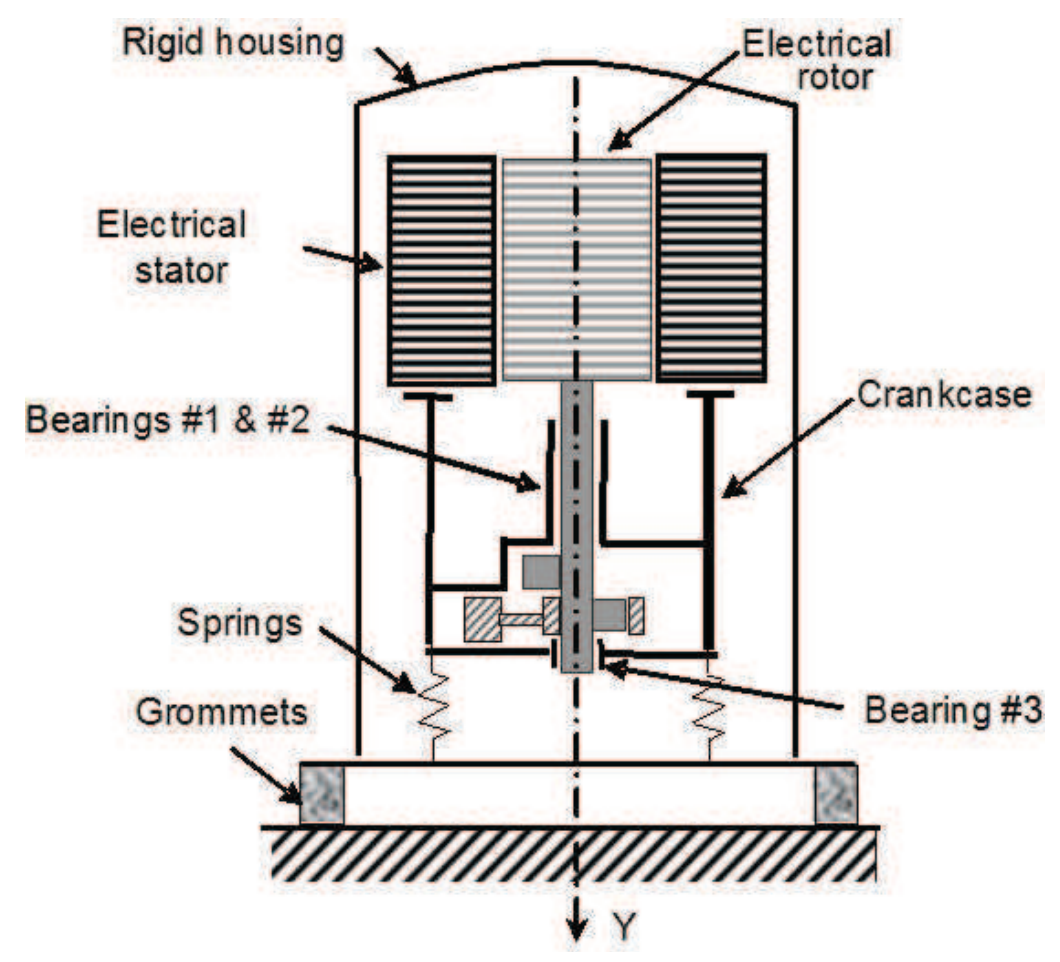

Figure 1: Compressor components. 


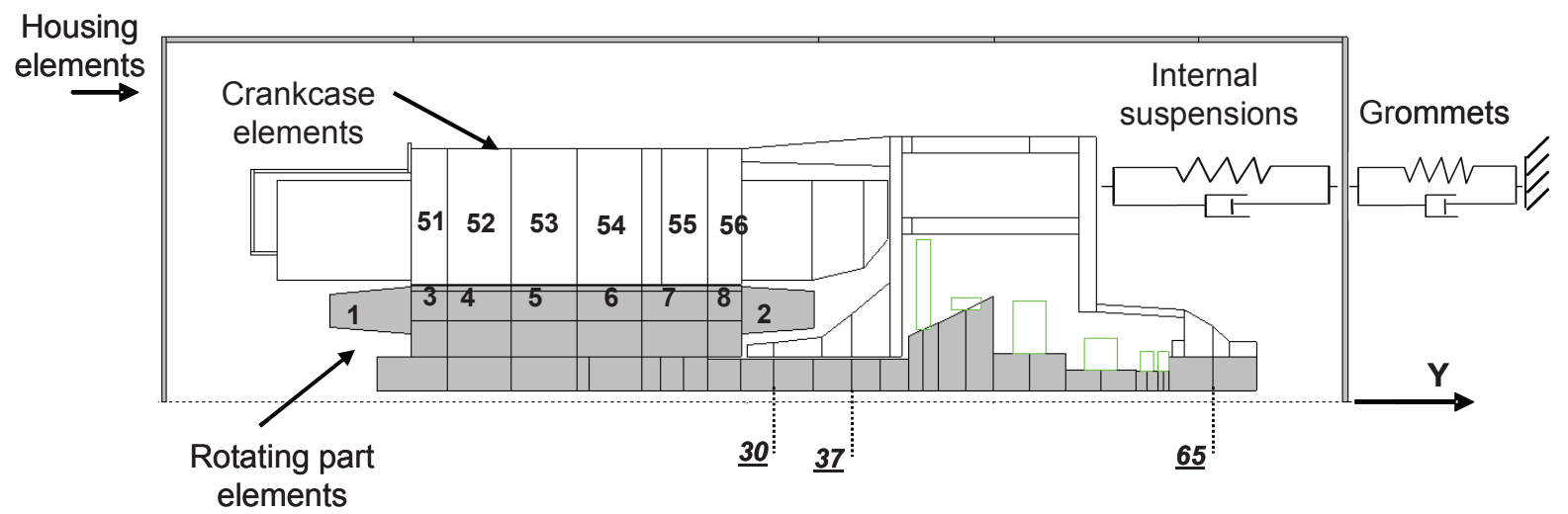

Figure 2: Finite-element model for the whole compressor 


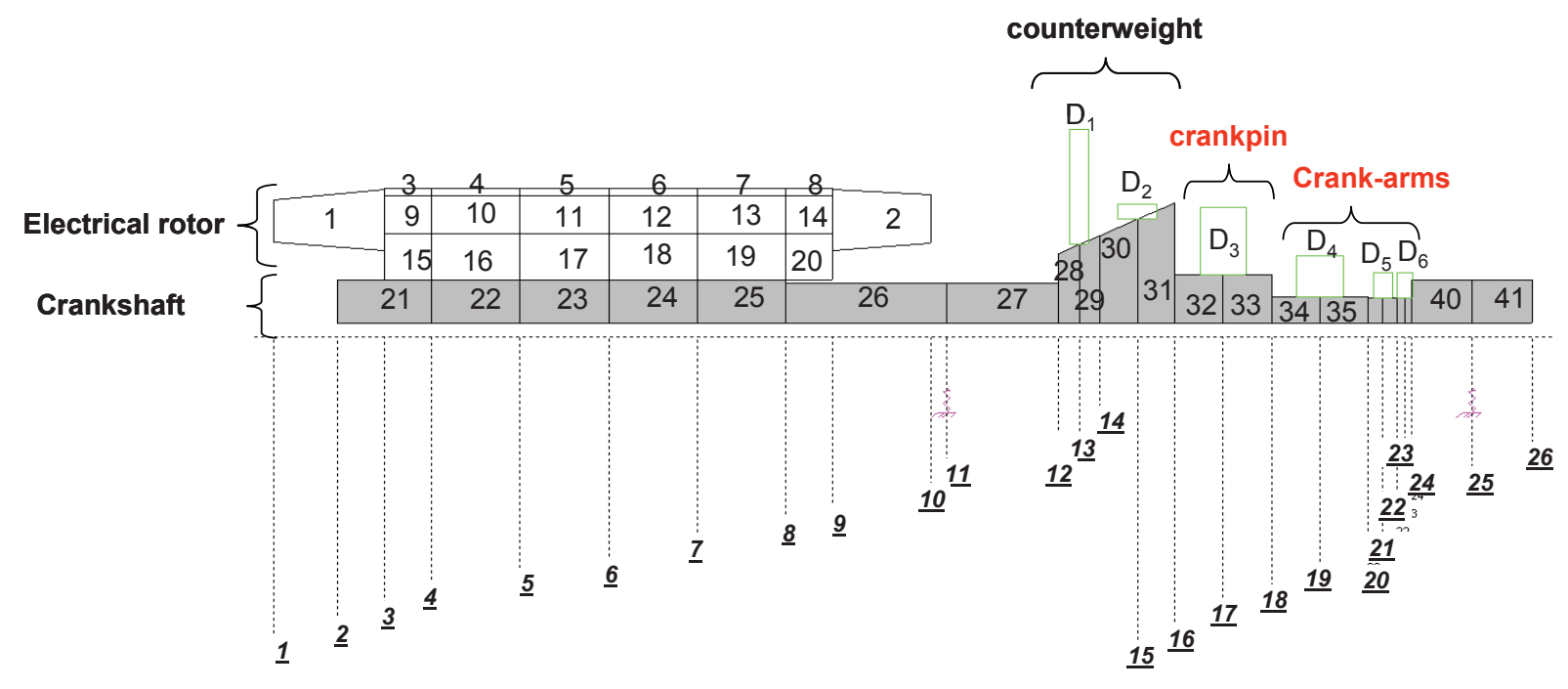

Figure 3. FE model of the rotating part (rotor-crankshaft assembly). 


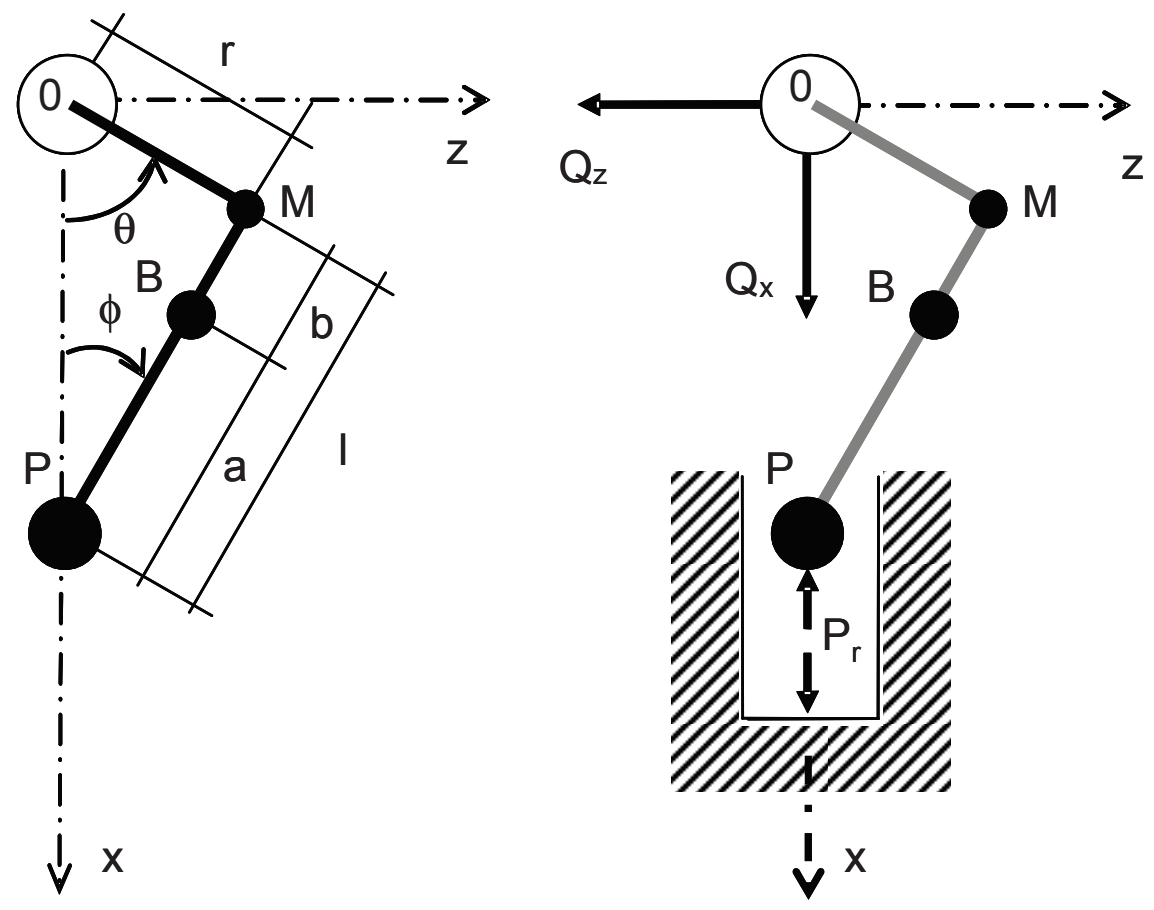

Figure 4. Slider-crank mechanism geometry and transmitted efforts. 

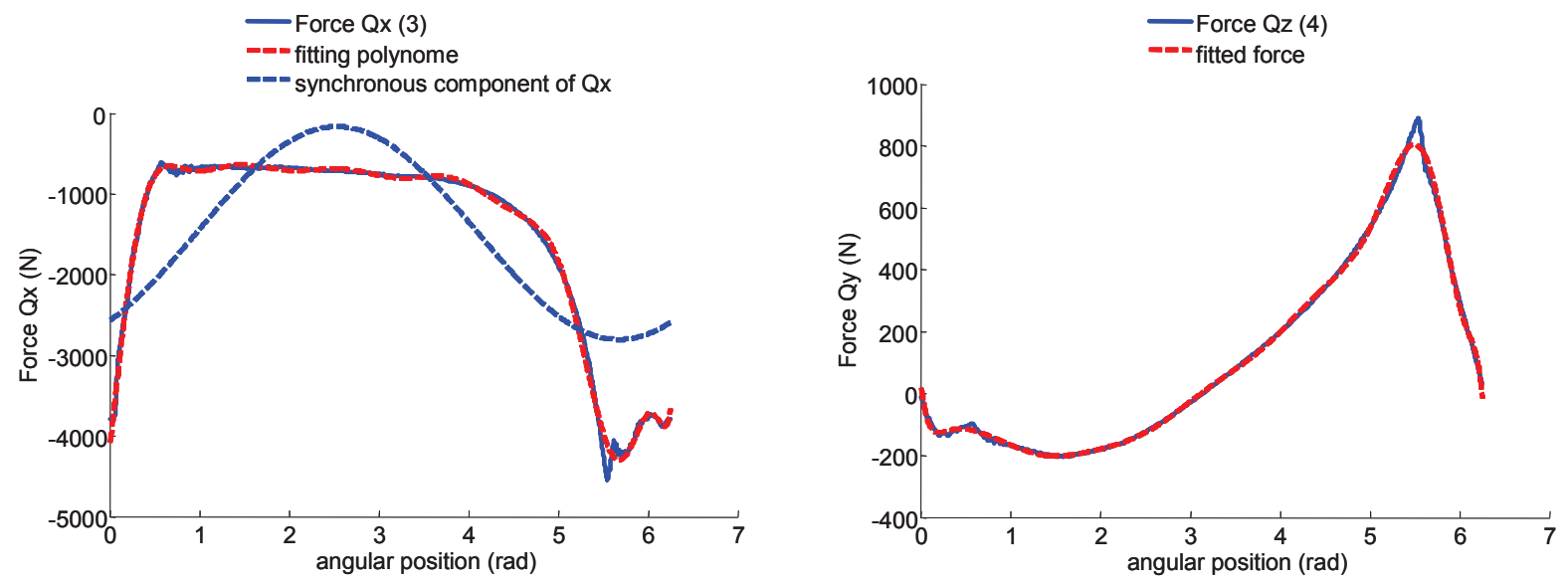

Figure 5. Evolution of the forces with the rotation angle. 

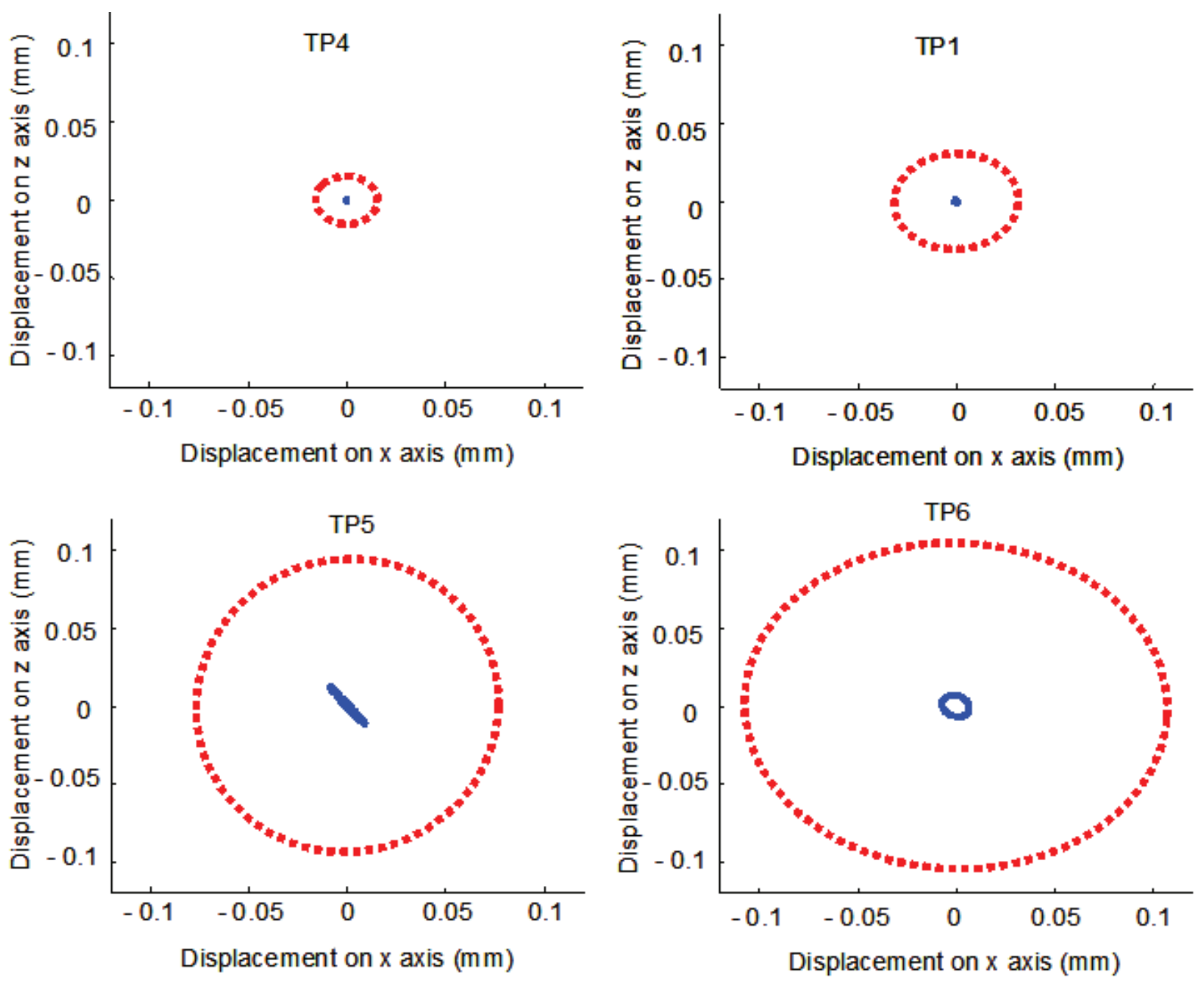

Figure 6. Predicted responses at target planes \#1, 4, 5 and 6 at $3000 \mathrm{r} / \mathrm{min}$ before (...... ) and after (_) the proposed balancing. 




Figure 7. Experimental set-up showing measurement points MP1, MP2 and MP3. 


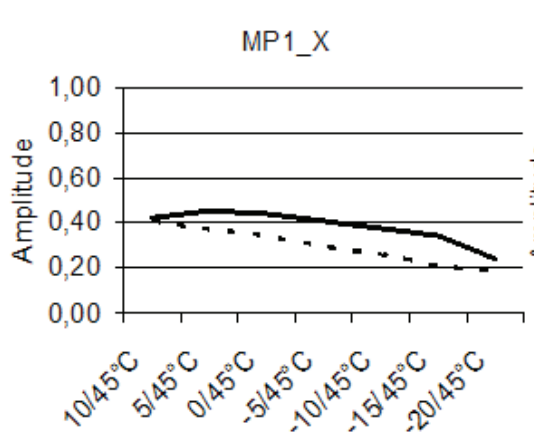

MP1_Y
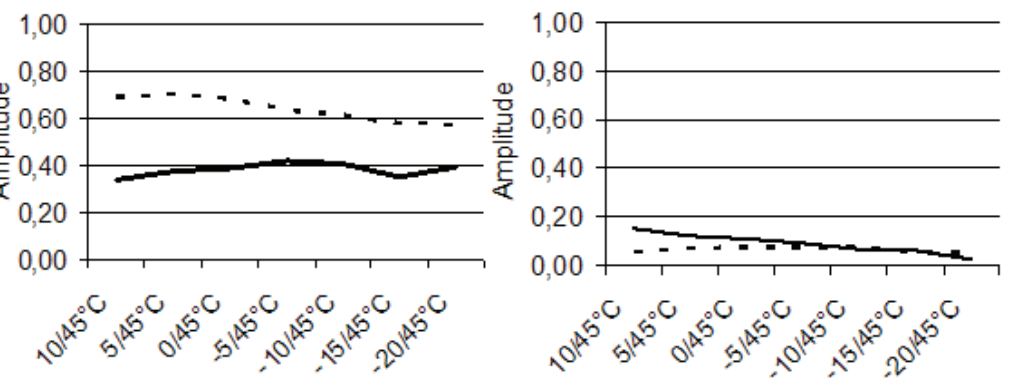

MP2_Y

MP3_Y
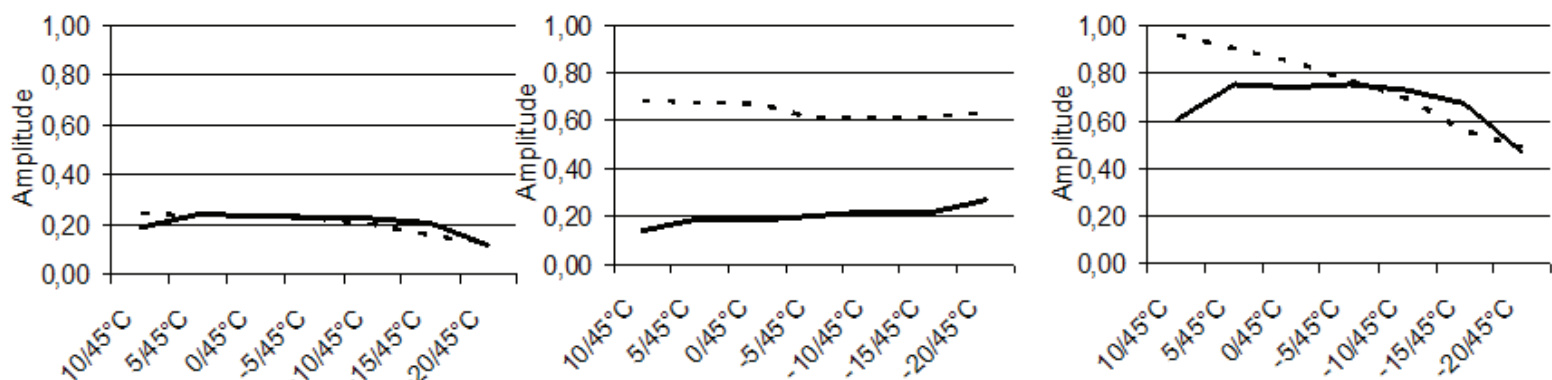

Figure 8. Dimensionless vibration levels versus operating conditions $-X$ and $Y$ directions at measurement points MP1, MP2 and MP3. Prototype\#1 with proposed balancing (_), Prototype\#2 with classical balancing (......). 